Acta Paediatr Sept 1992; $\underline{81: 686-690) . ~(C o r r e s p o n d e n c e: ~ D r . ~ M . ~ T h o m m e s s e n, ~ O s l o ~}$ City Department of Environmental Health, Saint Olavs plass 5, 0165 Oslo 1, Norway.)

COMMENT. The authors conclude that feeding problems and inadequate intake of nutrients contribute to the poor weight and growth of girls with Rett syndrome. Consultation with a dietician is important in children with Rett syndrome.

Rett syndrome in a pair of full sisters is reported from Sao Paulo, Brazil (Kok F et al. Pediatr Neurol Sept/Oct 1992; $\underline{8}: 381$ (abstract)). The occurrence of familial cases is very rare and up to now, 3 pairs of full sisters, 2 pairs of half sisters, and 1 aunt/niece pair had been reported. All 2 pairs of female dizygotic twins have been discordant and all 8 pairs of monozygotic twins have been concordant for the disease. The parents of the reported sisters with Rett syndrome were unrelated.

\title{
ANGELMAN SYNDROME: CHROMOSOME ABNORMALITY
}

Clinical cytogenetic and molecular evidence in 1 patient with paternal uniparental disomy (UPD) for chromosome 15 is reported from the University of Florida College of Medicine, Gainesville, FL. The deletions of chromosome 15 q11-q13 were demonstrated with DNA probes. Twenty-seven patients with a clinical diagnosis of Angelman syndrome were evaluated in the laboratory by molecular genetic techniques. Twenty had a molecular deletion of 15 q11-q13, whereas 6 had biparental inheritance for chromosome 15 DNA markers. The 7 th patient, who did not have a molecular deletion, had paternal UPD for chromosome 15. This is the first patient in whom UPD involved the critical chromosomal region. The overall frequency of paternal UPD was calculated at $3.7 \%$. The low frequency of UPD in Angelman syndrome contrasts with the high frequency of $25 \%$ for maternal UPD in Prader-Willi syndrome (Nicholls RD et al. Paternal uniparental disomy of chromosome 15

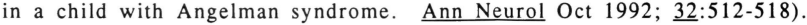
(Correspondence: Dr. Nicholls, Department of Neuroscience, Box 100244 JHMHC, University of Florida College of Medicine, Gainesville, FL 32610.)

COMMENT. Angelman syndrome is characterized by severe mental retardation, absence of speech, inappropriate laughter, puppet-like ataxic movements, microbrachycephaly, seizures, an abnormal electrocephalogram, mild hypotonia, hypopigmentation and prognathism with tongue protrusion. Most cases of Angelman syndrome are due to deletions of exclusively maternal origin from a critical region in chromosome 15 q11-q13. For a review of the diagnostic features of 36 cases of Angelman syndrome see Robb SA et al. Arch Dis Child Jan 1989; 64:83 and Progress in Pediatric Neurology, Millichap JG (ed), Chicago, PNB Publ, 1991, pages 487-88. 